\title{
Scottish Index of Multiple Deprivation (SIMD) Indicators as Predictors of Mortality Among Patients Hospitalised with COVID-19 Disease in the Lothian Region, Scotland During the First Wave: A Cohort Study
}

Marcello S Scopazzini ( $\sim$ marcello.scopazzini@nhslothian.scot.nhs.uk)

Clinical Infection Research Group, NHS Lothian Infection Service, Western General Hospital, UK

Roo Nicola Rose Cave

The Roslin Institute and Royal (Dick) School of Veterinary Studies, University of Edinburgh, UK Callum P Mutch

Clinical Infection Research Group, NHS Lothian Infection Service, Western General Hospital, UK

\section{Daniella A Ross}

Clinical Infection Research Group, NHS Lothian Infection Service, Western General Hospital, UK

\section{Anda Bularga}

British Heart Foundation Centre for Cardiovascular Science, University of Edinburgh, UK

\section{Margo Chase-Topping}

The Roslin Institute and Royal (Dick) School of Veterinary Studies, University of Edinburgh, UK Mark Woolhouse

Usher Institute, University of Edinburgh, UK

Oliver Koch

Clinical Infection Research Group, NHS Lothian Infection Service, Western General Hospital, UK Meghan R Perry

Clinical Infection Research Group, NHS Lothian Infection Service, Western General Hospital, UK Claire L Mackintosh

Clinical Infection Research Group, NHS Lothian Infection Service, Western General Hospital, UK

\section{Research Article}

Keywords: Deprivation, Covid-19, SIMD indicators, mortality

Posted Date: November 30th, 2021

DOI: https://doi.org/10.21203/rs.3.rs-1102651/v1

License: @ (i) This work is licensed under a Creative Commons Attribution 4.0 International License. Read Full License 


\section{Abstract}

Background: Sars-CoV-2, the causative agent of COVID-19, has led to more than 100,000 deaths in the UK and multiple risk factors for mortality including age, sex and deprivation have been identified. This study aimed to identify which indicators of Scottish Index of Multiple Deprivation (SIMD), an area-based deprivation index, were predictive of mortality.

Methods: This was a prospective cohort study of anonymised electronic health records of 710 consecutive patients hospitalised with Covid-19 disease between March and June 2020 in the Lothian Region of Southeast Scotland. Data sources included automatically extracted data from national electronic platforms and manually extracted data from individual admission records. Exposure variables of interest were SIMD quintiles and more specifically 12 indicators of deprivation deemed clinically relevant selected from the SIMD. Our primary outcome was mortality. Univariable and multivariable logistic regression analyses adjusted for age and sex were used to determine measures of association between exposures of interest and the primary outcome.

Results: After adjusting for age and sex, we found an increased risk of mortality in the more deprived SIMD quintiles 1 and 3 (OR 1.75, Cl 0.99-3.08, $\mathrm{p}=0.053$ and OR 2.17, Cl 1.22-3.86, p=0.009, respectively), but this association was not significant in our multivariable model adjusted for co-morbidities and clinical parameters of severity at admission. Of the 12 pre-selected indicators of deprivation, two were associated with greater mortality in our multivariable analysis: income deprivation rate categorised by quartile (Q4 (most deprived): $2.11(1.20-3.77) \mathrm{p}=0.011)$ ) and greater than expected hospitalisations due to alcohol per SIMD data zone $(1.96(1.28-3.00) \mathrm{p}=0.002))$.

Conclusions: In contrast to other studies, deprivation quintile distribution was not predictive of mortality in our cohort. This possibly reflects the greater affluence and ethnic homogeneity of the Lothian Region compared to the rest of Scotland. We identified an increased risk of mortality in patients residing in areas with greater income-deprivation and/or number of hospitalisations due to alcohol. In areas where aggregate measures fail to capture pockets of deprivation, specific indicators may be helpful in targeting resources to residents at risk of poorer outcomes from Covid-19.

\section{Introduction}

Coronavirus disease 2019 (Covid-19) first emerged in December 2020, in Wuhan, China, and has now contributed to more than 140,000 deaths in the UK ${ }^{1,2}$. Previous studies conducted in several different countries during the first wave identified being male and older, presence of comorbidities, and greater socioeconomic deprivation at diagnosis as major risk factors for death and intensive care unit (ICU) admission ${ }^{3-5}$.

Two large population-based studies - the OpenSAFELY Collaborative in England (June 2020) and the REACT-SCOT study in Scotland (October 2020) - have produced authoritative evidence that lower socio-economic status was associated with severe disease and mortality from Covid-19 even when adjusted for age, sex, and number of co-morbidities at presentation ${ }^{6,7}$. Scotland, with the unenviable sobriquet "the Sick Man of Europe", consistently ranks among the least healthy countries in Europe: multi-generational poverty and social exclusion, drug- and alcohol-dependence, and poor educational attainment have proved pervasively difficult to eradicate and continue to negatively impact health outcomes ${ }^{8,9}$.

The Scottish Index of Multiple Deprivation (SIMD) ranks geographical areas of similar population across seven standardised domains (income, employment, education, health, access to services, crime and housing) to target interventions aimed at alleviating social inequalities ${ }^{10}$. To date, studies have focused on how aggregate SIMD quintile rankings influence outcomes in Covid-19: in a recent national cohort study, patients in the lowest SIMD quintile admitted to intensive care in Scotland had a two-fold greater risk of death ${ }^{11}$. Studies looking at separate indicators of deprivation have shown that area-specific measures of income deprivation and overcrowding were predictive of poorer outcomes among affected residents, but, to date, other potentially relevant indicators within the SIMD have not been evaluated ${ }^{12}$.

In this study of 710 patients hospitalised with Covid-19 in the Lothian Region of South-East Scotland between March $1^{\text {st }}$ and June $30^{\text {th }}, 2020$, we investigated the impact of 12 clinically relevant individual SIMD indicators and constructed a model to determine their relationship with mortality in this cohort.

\section{Methods}

\section{Study setting and databases}

Data sources were linked using the Community Hospital Index (CHI), a unique identifier for patients resident in Scotland. Data were automatically extracted from the following platforms: laboratory information management systems, the Scottish Morbidity Record, the Scottish Drug Dispensing Database, and the Scottish Care Information Store.

Clinical and demographic data obtained from individual hospitalisation events were manually linked by a team of researchers at the Western General Hospital (Edinburgh, UK). Primary reasons for admission to ICU and mortality were adjudicated by the clinical research team to determine if Covid-19 was the principal contributor. Prior to analysis, all data were anonymised and stored in a data repository (DataLoch, Edinburgh, United Kingdom).

\section{Participants}

This was a prospective cohort study which included any patients aged $>16$ whose listed postcode was in one of East Lothian, City of Edinburgh, Midlothian, or West Lothian councils and who were admitted to hospital with a laboratory confirmed, positive polymerase chain reaction test for SARS-CoV-2 between 01/03/20 and 30/06/2020.

\section{Variables}


Our primary outcome was mortality. Secondary outcomes included: admission to intensive care unit (ICU); ventilator support, including non-invasive and invasive ventilation; and hospital length of stay.

The primary exposures of interest were Scottish Index of Multiple Deprivation (SIMD) indicators. The SIMD is an aggregate measure of deprivation that comprises seven domains (Income, Employment, Education, Health, Access to Services, Crime and Housing) further subdivided into 37 component indicators. The study team selected 12 indicators considered clinically relevant for final analysis (see table 1).

Other exposure variables were determined in a separate descriptive cohort study in the same group of patients (Mutch C, Bularga A, Perry M, Mackintosh C et al. - unpublished material, 2021). These included: demographic variables of age, sex, and ethnicity; World Health Organization (WHO) Performance Status, which categorises the impact of chronic disease severity on patient activity levels $(0=$ able to carry out normal activity without restriction; $1=$ restricted in strenuous activity but ambulatory; 2 = ambulatory for $>50 \%$ of waking hours; $3=$ symptomatic in a chair or bedridden for $>50 \%$ of waking hours; and $4=$ completely disabled); admission pulse, in beats per minute; admission haemoglobin, in units per decilitre; neutrophil and lymphocyte counts; creatinine level, in grams/decilitre; and SIMD quintile.

\section{Statistical analysis}

Continuous outcomes were categorised into standardised brackets with the normal reference range used as the reference variable (admission pulse, admission haemoglobin, admission neutrophil and lymphocyte counts) whilst age was categorised into age groups with age group 50-59 used as the reference variable. Continuous SIMD indicator variables were categorised into quartiles, with the lowest quartile (least deprived) used as the reference variable. For SIMD standardized ratios, the variable was categorized as greater than or less than expected occurrence (standardised ratio itself) in each data zone.

Correlation between SIMD indicator exposures variables was assessed using Cramer's V correlation coefficient.

Age- and sex-adjusted univariable analysis was carried out using logistic regression analysis (R Studio Version 3. 6. 1) to determine measures of association between mortality and the 12 selected indicators of deprivation (Table 1). Indicators that improved the model fit, as assessed by Akaike information criterion (AIC), and had a p-value $<0.157$ were carried forward into a multivariable model. Clinical variables were added to the multivariable model to assess whether the SIMD variables identified in the univariable model remained predictive of mortality ${ }^{13}$.

\section{Approvals}

Ethical approval was granted by the Lothian NHS Board (reference number CG/DF/2087). Linkage of anonymous datasets was performed by DataLoch, a data driven initiative designed to provide a secure repository of health and social care data in Southeast Scotland (Usher Institute, University of Edinburgh). Access to the final database was restricted to the core team of researchers with specific approvals and only accessible via a secure NHS network.

\section{Results}

\section{Baseline characteristics, symptoms, and clinical parameters at presentation}

Between March $1^{\text {st }}$ and June $30^{\text {th }}, 2020,726$ patients were admitted to one of three hospitals in the Lothian Region (East Lothian, Midlothian, City of Edinburgh, and West Lothian councils) with a positive polymerase chain reaction (PCR) for SARS-CoV-2. We excluded 13 patients from our analysis whose residential postcode was not within the Lothian Region, and three patients who did not have a registered postcode.

Case distribution by SIMD quintile was bimodal, with peaks in the second most deprived quintile (SIMD2: $\mathrm{n}=183,25.8 \%$ ) and least deprived quintile (SIMD 5: $\mathrm{n}=190,26.8 \%$ ) but differences in case numbers between quintiles were not statistically significant (see table 2). Median age was 73 (IQR $58-83$ ) and men accounted for $54.4 \%$ of patients. Age, sex, and ethnicity did not vary significantly across quintile. Performance status recorded at admission was graded at WHO stage 3 or more in just over a third of patients $(34.4 \%, n=245)$ and was distributed evenly across SIMD quintiles. Hypertension ( $n=292,41 \%)$, Diabetes $(n=166,23 \%)$ and unspecified cancers ( $n=144,20 \%)$ were the most commonly reported co-morbidities, and most patients had two or more co-morbidities ( $n=$ $407,57.3 \%$ ). Variation across SIMD quintiles did not differ significantly. Symptoms and clinical parameters of severity at presentation were similar in patients with co-morbidities.

\section{Outcomes}

Outcomes were available for all 710 patients included in the study (see table 3). Cause of death adjudicated to Covid-19 - defined as death occurring within 28 days of a positive PCR test for SARS-CoV-2 - was recorded in $28 \%(n=197)$ of patients; deaths were proportionately higher in patients in the most deprived quintile compared to the least deprived (SIMD $1-31 \%$ vs SIMD $5-26.8 \%$ ) and fewer patients received mechanical ventilator support in the most deprived quintile compared to the least deprived (SIMD $1-41.6 \%$ v SIMD $5-65.2 \%$ ). Data pertaining to suitability for intensive care and/or mechanical ventilation was not available for this study. Mean length of hospital stay was similar across SIMD quintiles.

\section{Correlation between clinically relevant indicators of deprivation and mortality}

To account for expected correlation between the 12 selected SIMD indicators selected for outcome analysis, a correlation matrix was created (see figure 1). This demonstrates that all variables were significantly inter-related, but, aside from standardized mortality ratio (SMR) and excessive admissions secondary to harmful drug use, none were significant correlated to age or sex.

\section{Associations between clinically relevant indicators of deprivation and mortality}


Increasing age, male sex, and poorer performance status at diagnosis were all significantly associated with mortality in our adjusted and unadjusted univariable regression model, but greater deprivation by SIMD quintile was non-significant (Quintile 1 (most deprived) $P=0.102$ ). We found no association between our secondary outcomes and greater deprivation. Of the 12 clinically relevant area-based indicators of deprivation we analysed for univariable analysis, two were significantly associated with mortality: greater income deprivation rate per data zone, categorized into quartiles (Quartile 4 (most deprived) $P=0.007)$ and greater than average admissions due to excess alcohol consumption per datazone $(p=0.009)$ (see table 4). This association persisted in our multivariable model (see table 4). Income rate and excess admissions due to alcohol per data zone were moderately correlated but no evidence of multicollinearity was detected in the final model.

\section{Comparative distribution of data zones between Lothian and the rest of Scotland}

We compared the distribution of data zones by SIMD quintile, income deprivation rate, and excess hospital admissions due to alcohol in Lothian and all of Scotland. SIMD quintile in Lothian demonstrated a bimodal distribution with a greater preponderance of data zones in SIMD quintiles 2 and 5 than the rest of Scotland (see figure 2a). We noted a lower median number and smaller distribution range when comparing distribution of datazones by income deprivation rate and higher-than-average hospitalisations secondary to alcohol in the Lothian Region compared to the rest of Scotland (see figures $\mathbf{2 b}$ and $\mathbf{2 c}$ ).

\section{Discussion}

In this study, we aimed to establish whether specific indicators of the Scottish Index of Multiple Deprivation (SIMD) were associated with mortality in a prospective cohort of patients admitted to hospital with Covid-19 disease in the Lothian Region between March $1^{\text {st }}$ and June $30^{\text {th }}, 2020$.

Previous studies have demonstrated an increased risk of death in patients living in more deprived communities in multiple countries ${ }^{3,6,7,11}$. We found an increased risk of death among age- and sex-adjusted patients in quintiles 1 and $3(\mathrm{OR} 1.75, \mathrm{Cl}$ 0.99-3.08, p=0.053 and OR 2.17, Cl 1.22-3.86, $\mathrm{p}=0.009$, respectively), but this association was not upheld in our multivariable model when adjusted for co-morbidities and clinical parameters of severity at presentation. We found no association between ICU admission and greater deprivation.

Importantly, SIMD scores are weighted calculations of each of the seven domains; Income and Employment domain are weighted twice as heavily as Health or Education in final aggregate scores ${ }^{10}$. We therefore selected 12 indicators of deprivation within the SIMD that could plausibly be linked to poorer outcomes in our cohort ${ }^{10}$. In our multivariable, age- and sex-adjusted regression model, we found a statistically significant risk of mortality among patients in areas that were more income deprived or reported higher-than-average numbers of alcohol-related hospital admissions.

We identified several factors that may explain the divergence in our results and contribute to the complexity of defining how deprivation, a multi-faceted entity where environmental, biological, social, economic, and educational factors interact over time, contributes to poorer outcomes in health.

Deprivation is a well-established risk factor for poorer health outcomes, but the underlying physiological mechanisms remain controversial. Some studies have proposed a biological link whereby increased inflammatory responses triggered by chronic social and environmental stress more common in deprived communities accelerate atherosclerosis and progression of dementia ${ }^{14-16}$, but few studies have sufficiently long follow-up periods to adequately account for confounders given the multifactorial nature of deprivation ${ }^{17-20}$

Deprivation has also been described as a barrier to accessing healthcare and, in Lothian, this is supported by recent evidence from the Infectious Diseases Outpatient Antibiotic Treatment (OPAT) that demonstrated that referrals were twice as likely to occur among patients belonging to the least deprived SIMD quintile 21 .

Because deprivation is multifactorial, its study relies on amalgamating a range of indicators to develop a detailed picture of residents in a specific location ${ }^{10,22,23}$. Indices of multiple deprivation (IMDs) such as the SIMD have gained traction as useful tools for governments to use to direct funds to specific locations based on the assumption that the spatial characteristics of a geographical locality's deprivation indicators affects the opportunities for poverty reduction for the entire population 22,24 .

The limitations of this approach are that IMDs fail to capture the key aspects of deprivation affecting any one individual and experienced general practitioners operating in "Deep End" practices that serve the most deprived communities in Scotland have called for increased devolution of healthcare in at-risk communities as well as heightened awareness of the impact of deprivation on health and health-seeking behaviour to reduce inequities in health ${ }^{25,26}$.

The Lothian region is comparatively more affluent than other regions of Scotland, and it is likely that using SIMD as a marker for individual deprivation fails to account for pockets of deprivation in the region that are not captured in the traditional quintile distribution of SIMD. Whilst we were not able to establish that deprivation by SIMD quintile was a risk factor for poorer outcomes in our cohort, the finding that patients who resided in datazones with greater income deprivation and greater-than-average admissions to hospital due to excess alcohol consumption had a significantly greater risk of death, suggests that a more granular analysis of deprivation indicators may help to identify individuals or groups at risk of greater mortality in areas where deprivation may be masked by greater overall affluence. The association between income deprivation and increased incidence and higher rates of hospitalization and mortality due to Covid19 is now well-established in both high- and low-income settings, further demonstrating the need for public health interventions to reduce barriers to testing, access to medical services, and mitigation of correlated risk factors for increased mortality such as obesity and co-morbidities ${ }^{27-30}$. Alcohol consumption, has, in contrast, not been found to be significantly associated with poorer outcomes, whether measured in terms of harmful intake in individuals ${ }^{31}$ or in spatial analyses of excessive alcohol consumption ${ }^{32}$. In our correlation matrix of our 12 pre-selected SIMD indicators of deprivation, our variable for higher-thanaverage admissions due to excessive alcohol consumption was strongly correlated to comparative illness factor - which measures how many individuals receive contributions for chronic disability - and employment, income, emergency room and drug-related admission rates per data zone. Our findings may

Page $4 / 12$ 
reflect the situation in Scotland, where excess hospitalizations and mortality due to harmful alcohol consumption are potentiated by inequality in income, educational attainment, and socio-economic class and may be a useful proxy marker for deprivation not captured elsewhere in the SIMD ${ }^{33}$.

Our study has several strengths. We were able to analyse a rich dataset of prospectively recruited individuals benefiting from integration of healthcare data extracted from multiple digital platforms into a centralized database. Our cohort study design enabled us to carry out a detailed analysis of deprivation-related exposures in relation to our outcomes of interest. We believe this is one of the few studies examining the role that specific indicators of deprivation in an IMD may play in contributing to poorer outcomes in patients hospitalized with Covid-19 disease.

Our study has several limitations. First, our study was restricted to hospitalized patients, and we are therefore unable to capture data on community transmission and outcomes in those not admitted to hospital. Another limitation is that the Lothian region is itself less representative than Scotland as a whole, with a greater proportion of its population being both more affluent and less likely to be from a minority ethnic group ${ }^{34}$. Other SIMD indicators not selected for logistic regression analysis may be strongly influencing results of SIMD that our researchers did not think relevant to health.

Finally, The SIMD is recognized as an imperfect tool that relies on area-specific characteristics to determine deprivation, and fails to capture non-spatial deprivation factors that contribute to poorer health outcomes among individuals ${ }^{17,20}$. Further, aggregate scores are weighted according to domain and assign a greater weight to income and employment deprivation than to health. Lastly, SIMD rankings are reviewed based on ten-year census data, which fail to capture between-census demographic change that may influence a specific data-zone's evolving deprivation ranking, for example, because of gentrification.

Our pilot study highlights interesting findings that shed light on the applicability of SIMD in determining outcomes in patients hospitalized with Covid-19. We plan to apply our model on a nationwide dataset to determine whether SIMD indicators may prove useful in targeting public health interventions to specific populations to improve outcomes. Further research could also consider increasing population-level subgrouping by applying our model to deciles of deprivation to better capture pockets of deprivation present in more affluent data-zones.

\section{Conclusion}

We present findings of a prospective cohort study of patients hospitalized with Covid-19 in the Lothian region recruited consecutively during the first wave of the Covid-19 pandemic. We performed unadjusted and age- and sex-adjusted univariable and multivariable analysis investigating the impact of specific indicators of deprivation on mortality. In contrast to other studies, greater deprivation as measured by quintile was not statistically significantly associated with poorer outcomes. Within specific indicators of deprivation, we found an association between data zones that were more income deprived and with greater than average number of hospitalizations related to excessive alcohol consumption and an increased risk of death and/or ICU admission. We propose that our findings are divergent due to the demographic characteristics of the Lothian population, which is generally more affluent and ethnically homogenous than the wider Scottish population and where up to $50 \%$ of deprived individuals live in non-deprived data zones ${ }^{24}$. We plan to apply our model to national datasets to investigate our findings further.

\section{Declarations}

\section{Ethics approval}

Ethical approval was granted by the Lothian NHS Board (reference number CG/DF/2087).

\section{Consent for publication}

Not Applicable.

\section{Availability of Data and materials}

The data that support the findings of this study are available from DataLoch (Edinburgh, United Kingdom) but restrictions apply to the availability of these data, which were used under license for the current study, and so are not publicly available. Data are however available from the authors upon reasonable request and with permission of DataLoch.

\section{Competing interests}

The authors declare that they have no competing interests.

\section{Funding}

Open Access and publication charges supported by the Wellcome Trust grant to the University of Edinburgh Library.

\section{Authors Contributions}

MRP, CLM, OK and MSS conceived the original design. DR, CPM, MRP and DataLoch collected the data, which was analysed by RNC and MSS with assistance from MRP and MCT. MS, RNC, MRP, and CLM drafted the manuscript which was critically revised by all authors who agree now to be accountable for all aspects of the work in ensuring that questions related to the accuracy and integrity of any part of the work are appropriately investigated and resolved.

\section{Acknowledgements}


DataLoch Covid-19 Collaboration: Atul Anand, Kathy Harrison, Catherine Stables, Ally Hume, David Homan, Catriona Waugh, Jilly McKay, Chris Duncan, Ronnie Harkess, Michael Gray, Colan Mahaffey, Pamela Linksted, Anoop S V Shah, Rob Baxter, Peter Cairns, Nicola Rigglesford, Martin Egan, Nicholas L Mills, Daniella A Ross, Claire L Mackintosh, Oliver Koch, Kate Templeton, Meghan R Perry, Anda Bularga, Hannah M M Preston, Thomas J McCormick, Arjuna A Sivakumaran, Kathryn A W Knight, Rosie Callender, Anna K Jamieson, Jonathan Wubetu, John P Kelly, Zaina Sharif, Ha Bao Trung Le, Jason Yang, Arun Parajuli, Ed Whittaker, Oscar C N Maltby, Sarah H Goodwin, Louisa R Cary, Emma K Watson, Thomas H Clouston, Julia Guerrero Enriquez, Xin Yi Ng, Kuan Ken Lee, Andrew R Chapman, Yvonne K McFarlane, Kate H Regan, Richard P Biggers, Anoop S V Shah, Alistair Stewart, Alastair Thomson, Daniella Ene, Hazel Neilson, Juergen Caris, Maria McMenemy, Nazir Lone, Paul Schofield, Sophie McCall, Stephen Young, Tracey McKinley, Tracey Rapson

\section{References}

1. Guan WJ, Ni ZY, Hu Y, et al. Clinical Characteristics of Coronavirus Disease 2019 in China. N Engl J Med. 2020 Apr 30;382(18):1708-1720.

2. Deaths in the UK | Coronavirus in the UK. [Accessed August 14, 2021]. https://coronavirus.data.gov.uk/details/deaths

3. Bray I, Gibson A, White J. Coronavirus disease 2019 mortality: a multivariate ecological analysis in relation to ethnicity, population density, obesity, deprivation and pollution. Public Health. 2020;185:261-263.

4. Dorn AV, Cooney RE, Sabin ML. COVID-19 exacerbating inequalities in the US. Lancet. 2020 Apr 18;395(10232):1243-1244.

5. Di Girolamo C, Bartolini L, Caranci N, Moro ML. Socioeconomic inequalities in overall and COVID-19 mortality during the first outbreak peak in EmiliaRomagna Region (Northern Italy). Epidemiol Prev. 2020;44(5-6 Suppl 2):288-296.

6. Williamson EJ, Walker AJ, Bhaskaran K, et al. OpenSAFELY: factors associated with COVID-19 death in 17 million patients. Nature. 2020 Aug;584(7821):430-436.

7. McKeigue PM, Weir A, Bishop J, et al. Rapid Epidemiological Analysis of Comorbidities and Treatments as risk factors for COVID-19 in Scotland (REACTSCOT): A population-based case-control study. PLOS Med. 2020;17(10):e1003374.

8. Whyte B, Ajetunmobi T. Glasgow Centre for Population Health (2012). Still "The Sick Man of Europe"? Scottish Mortality in a European Context 1950-2010: An analysis of comparative mortality trends.

https://www.gcph.co.uk/assets/0000/3606/Scottish_Mortality_in_a_European_Context_2012_v11_FINAL_bw.pdf [Accessed August 14, 2021]

9. Scotland I OECD Regional Well-Being. https://www.oecdregionalwellbeing.org/UKM.html [Accessed August 14, 2021]

10. The Scottish Index of Multiple Deprivation. Scottish Government. (https://www2.gov.scot/Topics/Statistics/SIMD) [Accessed August 14, 2021]

11. Lone NI, Mcpeake J, Stewart NI, et al. Influence of socioeconomic deprivation on interventions and outcomes for patients admitted with COVID-19 to critical care units in Scotland: A national cohort study. Lancet Reg Health Eur. 2021 Feb;1:100005.

12. Public Health England (2020). Disparities in the risk and outcomes of COVID-19. https://assets.publishing.service.gov.uk/government/uploads/system/uploads/attachment_data/file/908434/Disparities_in_the_risk_and_outcomes_of_c [Accessed Augst 14, 2021]

13. Teräsvirta T, Mellin I. Model Selection Criteria and Model Selection Tests in Regression Models. Scand J Stat. 1986;13(3):159-171.

14. Murayama H, Sugiyama M, Inagaki H, et al. The Differential Effects of Age on the Association Between Childhood Socioeconomic Disadvantage and Subjective Symptoms of Dementia Among Older Japanese People. J Epidemiol. 2019;29(7):241-246.

15. Cadar D, Lassale C, Davies H, et al. Individual and Area-Based Socioeconomic Factors Associated With Dementia Incidence in England: Evidence From a 12-Year Follow-up in the English Longitudinal Study of Ageing. JAMA Psychiatry. 2018;75(7):723-732.

16. Nash SD, Cruickshanks KJ, Klein R, et al. Socioeconomic Status and Subclinical Atherosclerosis in Older Adults. Prev Med. 2011;52(3-4):208.

17. Braveman P, Gottlieb L. The social determinants of health: it's time to consider the causes of the causes. Public Health Rep. 2014 Jan-Feb;129 Suppl 2(Suppl 2):19-31.

18. Mackes NK, Golm D, Sarkar S, et al. Early childhood deprivation is associated with alterations in adult brain structure despite subsequent environmental enrichment. Proc Natl Acad Sci U S A. 2020;117(1):641-649.

19. Velupillai, Y.N., Packard, C.J., Batty, G.D. et al. Psychological, social and biological determinants of ill health (pSoBid): Study Protocol of a populationbased study. BMC Public Health 8, 126 (2008).

20. Marmot M, Bell R. Social inequalities in health: A proper concern of epidemiology. Ann Epidemiol. 2016;26(4):238-240.

21. Sumpter C, Russell CD, Mackintosh C. Inequitable access to an outpatient parenteral antimicrobial therapy service: linked cross-sectional study. Int $J$ Equity Health. 2020;19:150.

22. Gordon D. Census based deprivation indices: their weighting and validation. Journal Epidemiol Community Heal. 1995;49(2):39-44.

23. McLoone P, Boddy F A. Deprivation and mortality in Scotland, 1981 and 1991 BMJ 1994; 309 :1465

24. Clelland D, Hill C. Deprivation, policy and rurality: The limitations and applications of area-based deprivation indices in Scotland. Local Economy. 2019;34(1):33-50.

25. Watt G, Brown G, Budd J et al. General Practitioners at the Deep End: The experience and views of general practitioners working in the most severely deprived areas of Scotland. Occas Pap R Coll Gen Pract. 2012 Apr;(89):i-40.

26. Fischbacher CM. Alternatives to SIMD for Targeting Anticipatory Care Identifying "Deprived Individuals": Are There Better Alternatives to the Scottish Index of Multiple Deprivation (SIMD) for Socioeconomic Targeting in Individually Based Programmes Addressing Health Inequalities in Scotland? http://www.scotland.gov.uk/Topics/Statistics/SIMD/deprivedruralpaper [Accessed May 9, 2021.] 
27. Jannot A-S, Countouris $\mathrm{H}$, Straaten A Van, et al. Low-income neighbourhood was a key determinant of severe COVID-19 incidence during the first wave of the epidemic in Paris. J Epidemiol Community Heal. 2021;0:1-4.

28. Das A, Ghosh S, Das K, et al. Modeling the effect of area deprivation on COVID-19 incidences: a study of Chennai megacity, India. Public Health. 2020;185:266-269.

29. Bilal U, Tabb LP, Barber S, Diez Roux AV. Spatial Inequities in COVID-19 Testing, Positivity, Confirmed Cases, and Mortality in 3 U.S. Cities : An Ecological Study. Ann Intern Med. 2021 Jul;174(7):936-944.

30. Baena-Díez JM, Barroso M, Cordeiro-Coelho SI, et al. Impact of COVID-19 outbreak by income: hitting hardest the most deprived. J Public Health (Oxf). 2020 Nov 23;42(4):698-703.

31. Hamer M, Kivimäki M, Gale CR, et al. Lifestyle risk factors, inflammatory mechanisms, and COVID-19 hospitalization: A community-based cohort study of 387,109 adults in UK. Brain Behav Immun. 2020 Jul;87:184-187.

32. Pro G, Gilbert PA, Baldwin JA, et al. Multilevel modeling of county-level excessive alcohol use, rurality, and COVID-19 case fatality rates in the US. PLoS One. 2021;16(6):e0253466.

33. Katikireddi SV, Whitley E, Lewsey J, et al. Socioeconomic status as an effect modifier of alcohol consumption and harm: analysis of linked cohort data. Lancet Public Heal. 2017;2(6):e267-e276.

34. Scottish Government (2011). Scotland's Census - Area Overview - Results for 2011. Accessed August 14, 2021. https://www.scotlandscensus.gov.uk/search-the-census\#/explore/snapshot

\section{Tables}

Table 1 - Indicators of Scottish Index of Multiple Deprivation deemed clinically relevant to analysis.

\section{SIMD Indicator}

Income Deprivation Rate

Employment Deprivation Rate

Comparative Illness Factor

Hospital stays related to alcohol use

Hospital stays related to drug use

Standardised Mortality Ratio

Proportion of population prescribed drugs for anxiety, depression, and/or psychosis

Emergency stays in hospital

Proportion of working age population with no higher qualifications

Drive to GP

Public Transport to GP

Overcrowding rate

\section{Description}

Percentage of residents who are income deprived, per datazone

Percentage of residents who are employment deprived, per datazone

Age and Sex standardised ratio of observed and expected number of recipients of disability allowance, per datazone

Age and sex standardised ratio of observed and expected hospital admissions with alcohol-related conditions

Age and sex standardised ratio of observed and expected hospital admissions with drug-related conditions

Age and sex standardised ratio of observed and expected all-cause death, per datazone

Estimated proportion of residents, per datazone

Age and sex standardised ratio of observed and expected emergency room hospital visits, per datazone

Proportion of residents, per datazone

Average driving time to nearest GP surgery, in minutes

Average travel time by public transport to nearest GP surgery, in minutes

Percentage of households that are overcrowded, per datazone

Table 2 - Summary of anthropometric and clinical characteristics of patients included in study stratified by SIMD quintile. *, continuous variables are presented as median (Interquartile range). Categorical variables are presented as number (\%). 


\begin{tabular}{|c|c|c|c|c|c|c|c|}
\hline & & All Patients & $\begin{array}{l}1=\text { Most } \\
\text { Deprived }\end{array}$ & 2 & 3 & 4 & $\begin{array}{l}5=\text { Least } \\
\text { Deprived }\end{array}$ \\
\hline & $\mathrm{N}, \%$ & 710 & $103(14.5 \%)$ & $\begin{array}{l}183 \\
(25.8 \%)\end{array}$ & $\begin{array}{l}102 \\
(14.4 \%)\end{array}$ & $\begin{array}{l}132 \\
(18.6 \%)\end{array}$ & $190(26.8 \%)$ \\
\hline $\begin{array}{l}\text { Age on admission* } \\
\text { (years) }\end{array}$ & & $73(58-83)$ & $73(60-82)$ & $72(57-81)$ & $68(53-81)$ & $\begin{array}{l}70.5(54- \\
82)\end{array}$ & $78(64-86)$ \\
\hline \multirow[t]{2}{*}{ Sex } & Male & $\begin{array}{l}386 \\
(54.4 \%)\end{array}$ & $50(48.5 \%)$ & $96(52.5 \%)$ & $55(53.9 \%)$ & $83(62.9 \%)$ & $102(53.7 \%)$ \\
\hline & Female & $\begin{array}{l}324 \\
(45.6 \%)\end{array}$ & $53(51.5 \%)$ & $87(47.5 \%)$ & $47(46.1 \%)$ & $49(37.1 \%)$ & $88(46.3 \%)$ \\
\hline \multirow[t]{3}{*}{ Ethnicity } & White & $\begin{array}{l}551 \\
(77.6 \%)\end{array}$ & $77(74.7 \%)$ & $\begin{array}{l}140 \\
(76.5 \%)\end{array}$ & $77(75.5 \%)$ & $107(81 \%)$ & $150(78.9 \%)$ \\
\hline & Black, Asian, Minority Ethnic & $28(4 \%)$ & $7(6.8 \%)$ & $10(5.5 \%)$ & $5(4.9 \%)$ & * & * \\
\hline & Ethnicity not recorded & $\begin{array}{l}131 \\
(18.4 \%)\end{array}$ & $19(18.4 \%)$ & $33(18 \%)$ & $20(19.6 \%)$ & $22(16.7 \%)$ & $37(19.5 \%)$ \\
\hline \multicolumn{8}{|l|}{$\begin{array}{l}\text { Previous Health } \\
\text { status }\end{array}$} \\
\hline \multirow[t]{6}{*}{ Performance status } & 0 & $\begin{array}{l}201 \\
(28.3 \%)\end{array}$ & $24(23.3 \%)$ & $42(22.9 \%)$ & $34(33.3 \%)$ & $44(33.3 \%)$ & $57(30 \%)$ \\
\hline & 1 & $\begin{array}{l}131 \\
(18.4 \%)\end{array}$ & $16(15.5 \%)$ & $46(25.1 \%)$ & $18(17.6 \%)$ & $23(17.4 \%)$ & $28(14.7 \%)$ \\
\hline & 2 & $\begin{array}{l}130 \\
(18.3 \%)\end{array}$ & $23(22.3 \%)$ & $38(20.7 \%)$ & $23(22.5 \%)$ & $22(16.7 \%)$ & $24(12.6 \%)$ \\
\hline & 3 & $200(28.1 \%)$ & $34(33 \%)$ & $47(25.7 \%)$ & $21(20.6 \%)$ & $32(24.2 \%)$ & $66(34.7 \%)$ \\
\hline & 4 & $45(6.3 \%)$ & $6(5.8 \%)$ & $9(4.9 \%)$ & $6(5.9 \%)$ & $10(7.6 \%)$ & $14(7.4 \%)$ \\
\hline & Missing & $<5$ & - & $<5$ & - & $<5$ & $<5$ \\
\hline \multirow[t]{3}{*}{ Co-morbidity count } & 0 & $\begin{array}{l}111 \\
(15.6 \%)\end{array}$ & $15(14.6 \%)$ & $23(12.6 \%)$ & $22(21.6 \%)$ & $22(16.7 \%)$ & $29(15.3 \%)$ \\
\hline & 1 & $192(27 \%)$ & $24(23.3 \%)$ & $48(26.2 \%)$ & $25(24.5 \%)$ & $35(26.5 \%)$ & $60(31.6 \%)$ \\
\hline & 2 plus & $\begin{array}{l}407 \\
(57.3 \%)\end{array}$ & $64(62.1 \%)$ & $\begin{array}{l}112 \\
(61.2 \%)\end{array}$ & $55(53.9 \%)$ & $75(56.8 \%)$ & $101(53.1 \%)$ \\
\hline \multicolumn{8}{|l|}{ Comorbidities } \\
\hline & $\begin{array}{l}\text { Chronic Obstructive Pulmonary } \\
\text { Disease }\end{array}$ & $104(15 \%)$ & $21(20 \%)$ & $28(27 \%)$ & $11(11 \%)$ & $21(20 \%)$ & $23(22 \%)$ \\
\hline & Diabetes Mellitus & $166(23 \%)$ & $27(16 \%)$ & $57(34 \%)$ & $22(13 \%)$ & $31(19 \%)$ & $29(18 \%)$ \\
\hline & Hypertension & $292(41 \%)$ & $41(14 \%)$ & $78(27 \%)$ & $44(15 \%)$ & $55(19 \%)$ & $74(25 \%)$ \\
\hline & Cancer & $144(20 \%)$ & $19(13 \%)$ & $31(22 \%)$ & $15(10 \%)$ & $32(22 \%)$ & $47(33 \%)$ \\
\hline & Other & & & & & & \\
\hline \multicolumn{8}{|l|}{$\begin{array}{l}\text { Symptoms on } \\
\text { presentation }\end{array}$} \\
\hline & Fever & $428(60 \%)$ & $60(58 \%)$ & $110(60 \%)$ & $62(60 \%)$ & $85(64 \%)$ & $111(58 \%)$ \\
\hline & Cough & $478(67 \%)$ & $67(65 \%)$ & 119 (65\%) & 75 (73\%) & 89 (67\%) & $128(67 \%)$ \\
\hline & Breathlessness & $419(59 \%)$ & $59(57 \%)$ & $116(63 \%)$ & $55(54 \%)$ & $87(66 \%)$ & $102(54 \%)$ \\
\hline \multicolumn{8}{|l|}{ Clinical parameters * } \\
\hline & $\mathrm{PaO} 2(\mathrm{kPa})$ & $\begin{array}{l}10.5(9.2 \\
12.8)\end{array}$ & $\begin{array}{l}11.5(9.2 \\
14.3)\end{array}$ & $\begin{array}{l}10.9(8.7 \\
12.8)\end{array}$ & $\begin{array}{l}10.7(9.2 \\
12.8)\end{array}$ & $\begin{array}{l}10.5(9.1 \\
12.8)\end{array}$ & $\begin{array}{l}10.9(9.2 \\
12.8)\end{array}$ \\
\hline & Pulse (bpm) & $\begin{array}{l}91(80 \\
105)\end{array}$ & $90(80,104)$ & $\begin{array}{l}90(80 \\
103)\end{array}$ & $\begin{array}{l}92(82 \\
105)\end{array}$ & $\begin{array}{l}94(85 \\
109)\end{array}$ & $90(76,103)$ \\
\hline & Respiratory Rate (breaths/min) & $21(18,26)$ & $20(18,24)$ & $20(18,24)$ & $22(18,28)$ & $22(20,26)$ & $20(18,24)$ \\
\hline
\end{tabular}

Table 3 - Outcomes for patients included in analysis stratified by SIMD quintile. 


\begin{tabular}{|llllllll|}
\hline & & All patients & $\mathbf{1}=$ Most deprived & $\mathbf{2}$ & $\mathbf{3}$ & $\mathbf{4}$ & $\mathbf{5}=$ least deprived \\
\hline & $\mathrm{N}$ & 710 & 103 & 183 & 102 & 132 & 190 \\
\hline Outcome & & & & & & & \\
\hline Dead & $\mathrm{N}(\%)$ & $197(28 \%)$ & $32(31 \%)$ & $47(25.7 \%)$ & $31(30.4 \%)$ & $36(27.2 \%)$ & $51(26.8 \%)$ \\
\hline Admission to ICU & $\mathrm{N}(\%)$ & $103(15 \%)$ & $12(11.6 \%)$ & $29(15.8 \%)$ & $19(17.6 \%)$ & $20(15.1 \%)$ & $23(12 \%)$ \\
\hline Required mechanical ventilation & $\mathrm{N}(\%)$ & $68(66 \%)$ & $5(41.6 \%)$ & $19(65.5 \%)$ & $13(68.4 \%)$ & $16(80 \%)$ & $15(65.2 \%)$ \\
\hline Length of hospital stay & Median (IQR) & $8(3,19)$ & $7(3,16)$ & $9(3,22)$ & $9(4,19)$ & $8(3,19)$ & $9(3,19)$ \\
\hline
\end{tabular}

Table 4 - Logistic Regression models of the association between mortality and: demographic indicators, indicators of severity on admission, socioeconomic deprivation stratified by quintile, income deprivation rate and greater than expected admissions due to alcohol per datazone. Univariable analysis results include both unadjusted and adjusted (for age and sex) values. Multivariable analysis undertaken for SIMD quintile, income rate, and hospital admissions related to alcohol. Multivariable analysis was adjusted for age, sex, co-morbidities and clinical parameters at the time of admission. 


\begin{tabular}{|c|c|c|c|c|}
\hline & & Unadjusted & Age and Sex-adjusted & \\
\hline \multirow[t]{5}{*}{ Age brackets (years) } & $50-59$ & - & - & \\
\hline & $<50$ & $0.26(0.04-1.05) p=0.090$ & $0.28(0.04-1.15) p=0.112$ & \\
\hline & $60-69$ & $4.16(1.86-10.29) p=0.001$ & $\begin{array}{l}4.26(1.90-10.55) \\
p=0.001\end{array}$ & \\
\hline & $70-79$ & $5.13(2.44-12.16) p<0.001$ & $\begin{array}{l}5.38(2.55-12.79) \\
p<0.001\end{array}$ & \\
\hline & $>79$ & $9.96(4.90-23.08) p<0.001$ & $\begin{array}{l}11.02(5.39-25.69) \\
p<0.001\end{array}$ & \\
\hline \multirow[t]{2}{*}{ Sex } & Female & - & - & \\
\hline & Male & $1.58(1.13-2.22) p=0.008$ & $1.80(1.25-2.60) p=0.002$ & \\
\hline \multirow[t]{5}{*}{ Performance Status } & 0 & - & - & \\
\hline & 1 & $4.32(2.24-8.71) p<0.001$ & $2.24(1.08-4.78) p=0.033$ & \\
\hline & 2 & $7.82(4.18-15.46) p<0.001$ & $\begin{array}{l}3.75(1.78-8.24) p= \\
<0.001\end{array}$ & \\
\hline & 3 & $\begin{array}{l}9.09(5.07-17.40) \\
p<0.0001\end{array}$ & $3.74(1.81-8.09) p=0.001$ & \\
\hline & 4 & $\begin{array}{l}12.77(5.83-29.03) \\
p<0.001)\end{array}$ & $\begin{array}{l}7.11(2.85-18.30) \\
p<0.001\end{array}$ & \\
\hline \multirow[t]{3}{*}{ Heart rate on admission (beats per minute) } & $60-99$ & - & & \\
\hline & $<60$ & $2.22(0.78-6.08) p=0.121$ & $1.29(0.44-3.67) p=0.628$ & \\
\hline & $>99$ & $1.26(0.88-1.78) p=0.207$ & $1.92(1.28-2.88) p=0.002$ & \\
\hline \multirow[t]{3}{*}{ Haemoglobin concentration (g/L) } & $>129$ & - & & \\
\hline & $<100$ & $3.66(2.03-6.69) p<0.001$ & $2.92(1.50-5.80) p=0.002$ & \\
\hline & $100-129$ & $1.10(0.77-1.58) p=0.587$ & $0.82(0.54-1.27) p=0.331$ & \\
\hline \multirow[t]{3}{*}{ Neutrophil count $\left(\times 10^{5}\right)$} & $2-7.5$ & - & & \\
\hline & $<2$ & $1.77(0.92-3.28) p=0.077$ & $2.26(1.10-4.59) p=0.025$ & \\
\hline & $>7.5$ & $1.73(1.18-2.53) p=0.004$ & $1.61(1.07-2.43) p=0.022$ & \\
\hline \multirow[t]{3}{*}{ Lymphocyte count $\left(\times 10^{5}\right)$} & $>1.4$ & - & & \\
\hline & $<0.5$ & $2.73(1.56-4.86) p=0.0001$ & $1.77(0.96-3.30) p=0.071$ & \\
\hline & $0.5-1.4$ & $1.18(0.75-1.91) p=0.471$ & $0.83(0.50-1.39) p=0.476$ & \\
\hline \multirow[t]{3}{*}{ Creatinine (mg/dl) } & $<125$ & - & & \\
\hline & $125+$ & $3.76(2.58-5.52) p<0.001$ & $2.46(1.63-3.70) p<0.001$ & \\
\hline & & & & Multivariable \\
\hline \multirow[t]{5}{*}{ SIMD quintile } & 5 (least deprived) & - & & 1 (ref) \\
\hline & 4 & $1.02(0.68-1.68) p=0.932)$ & $1.35(0.78-2.33) p=0.284$ & $\begin{array}{l}1.13(0.61-2.07) \\
p=0.692\end{array}$ \\
\hline & 3 & $1.19(0.67-2.01) p=0.520)$ & $1.91(1.06-3.45) p=0.032$ & $\begin{array}{l}1.59(0.84-3.02) \\
p=0.155\end{array}$ \\
\hline & 2 & $0.94(0.59-1.49) p=0.799)$ & $1.24(0.75-2.05) p=0.393$ & $\begin{array}{l}1.25(0.72-2.16) \\
p=0.425\end{array}$ \\
\hline & 1 (most deprived) & $1.23(0.72-2.07) p=0.444)$ & $1.61(0.91-2.85) p=0.102$ & $\begin{array}{l}1.55(0.84-2.87) \\
p=0.162\end{array}$ \\
\hline \multirow[t]{4}{*}{ Income rate, categorised by quartile } & $\begin{array}{l}\text { Q1 (least } \\
\text { deprived) }\end{array}$ & - & & 1 (ref) \\
\hline & Q2 & $1.53(0.93-2.55) p=0.093$ & $2.00(1.17-3.46) p=0.018$ & $\begin{array}{l}1.87(1.04-3.39) \\
p=0.038\end{array}$ \\
\hline & Q3 & $1.17(0.71-1.96) p=0.532$ & $1.70(0.99-2.96) p=0.056$ & $\begin{array}{l}1.61(0.90-2.92) \\
p=0.114\end{array}$ \\
\hline & $\begin{array}{l}\text { Q4 (most } \\
\text { deprived) }\end{array}$ & $1.42(0.88-2.32) p=0.157)$ & $2.05(1.22-3.51) p=0.007$ & $\begin{array}{l}2.11(1.20-3.77) \\
p=0.011\end{array}$ \\
\hline
\end{tabular}

Page 10/12 


\section{Figures}

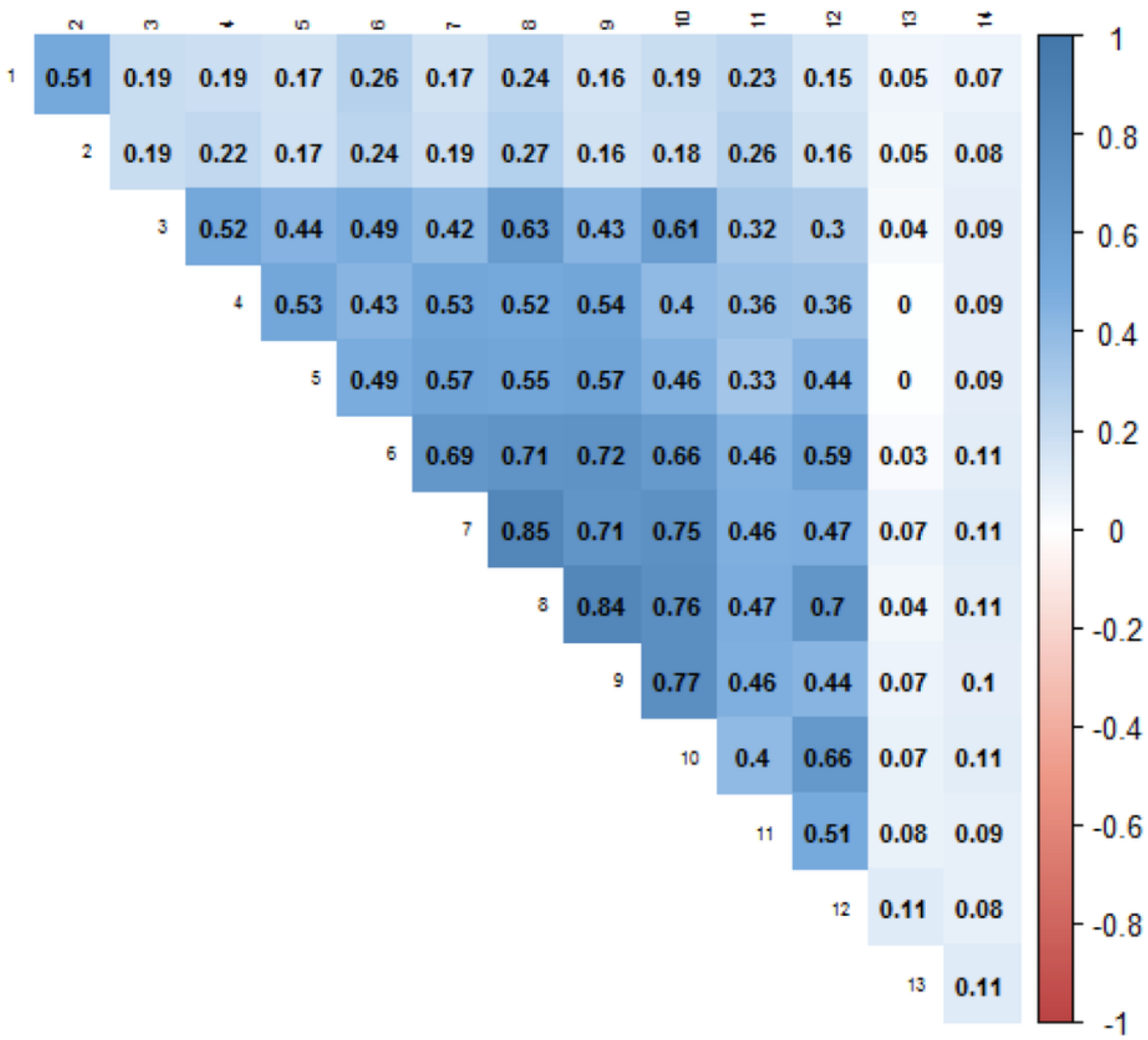

Figure 1

Cramer's V Correlation Matrix of 12 selected indicators of deprivation plus age and sex. Deeper shading indicates higher degree of correlation. Legend: 1. Distance to nearest GP surgery per datazone, in minutes; 2. Distance to nearest GP surgery by public transport per datazone, in minutes; 3 . Overcrowding rate; 4. Hospitalisations due to alcohol per datazone; 5 . Hospitalisations due to illicit drug use per datazone; 6 . Emergency hospitalisations per datazone; 7. Employment rate; 8 . Comparative Illness factor; 9 . Income rate; 10. 16-19 year-olds without qualifications; 11 . Standardised Mortality Ratio; 12 . Prescriptions for anxiety, depression or psychosis per datazone; 13. Sex; 14. Age.

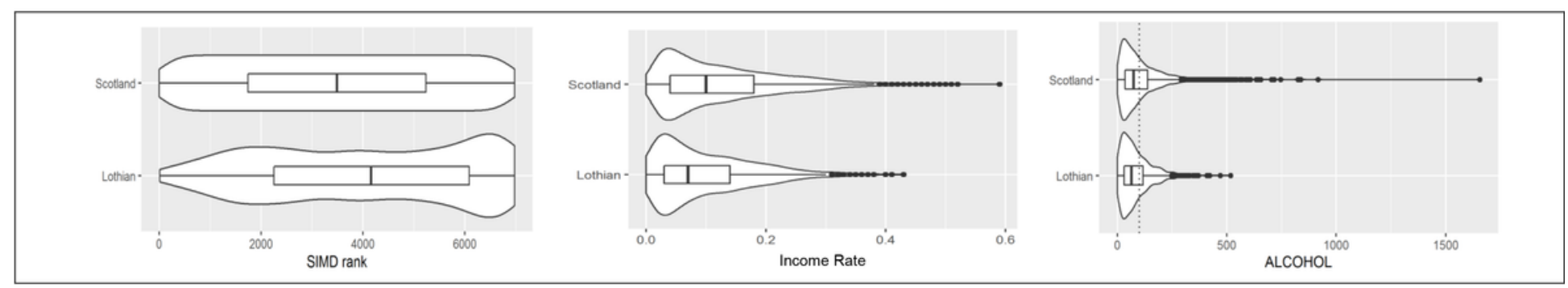


Figure 2

Violin plots. 2a. the shape of the distribution of SIMD rank, in Lothian compared to Scotland. SIMD rank of 1 is most deprived and 6976 is least deprived. $2 \mathrm{~b}$. the shape of the distribution of Income deprivation rate in Lothian compared to Scotland. 2c. the shape of the distribution of datazones according to number of hospitalisations related to alcohol; this is a standardised ratio where 100 (dotted line) represents the expected number. 